\title{
Comprehensive Approach to Curriculum Design for Advanced Training of Academic Staff in the Direction "Radio Electronic Devices and Systems" in Uzbekistan
}

\author{
Shakhnoza Pozilova, Khaydar Madaminov, Golibjon Otamurodov, Umida Murtazaeva, and Feruza \\ Zakirova
}

\begin{abstract}
Education should be developed parallel to the development of science and technology. Research in the field of Space Radio Electronic Communication Systems is currently being updated. Their use without training and advanced training of national personnel will be ineffective. Therefore, the education system, in particular the Advanced Training System, must respond to these changes in a timely manner. The article considers an integrated approach to designing a curriculum for advanced training courses on the example of the direction "Radio Electronic Devices and Systems" for academic staff of Higher Education, which involves the design of a curriculum based on an analysis of the needs of academic staff and an analysis of professional competencies necessary for the organization of scientific and pedagogical activities in Higher Education in the conditions of digitalization of education.
\end{abstract}

Index Terms-Curriculum design, higher education, professional development, space communication.

\section{INTRODUCTION}

Development of technologies of the XXI century leads to radical changes in many spheres of life, including in the education system of the Republic of Uzbekistan. Despite the positive changes that have occurred in the education system over the years of Independence, the state, based on the needs of society, constantly regulates the mechanisms of their organization.

The system of advanced training and retraining of personnel on the basis of Article 10 of the Law on Education of the Republic of Uzbekistan, adopted in 1997, has become an independent type of training, which is designed to deepen and update the professional knowledge and skills of national staff. Based on the Decree of the President of the Republic of Uzbekistan No. 4732 "About measures on further

Manuscript received February 20, 2020; revised November 10, 2020

S. Posilova is with Department of Information Technologies on Education, Tashkent University of Information Technologies, Uzbekistan (e-mail: informatikpozilova@gmail.com).

K. Madaminov is with Department of Technology Mobile Communications, Tashkent University of Information Technologies, Uzbekistan (e-mail: h.madaminov1978@gmail.com).

G. Otamurodov is with Head Scientific and Methodological Center under the Ministry of Higher and Secondary Specialized Education of the Republic of Uzbekistan, Uzbekistan (e-mail: foniy_02_03@mail.ru).

U. Murtazaeva is with Department of Computer System, Samarkand Branch of the Tashkent University of Information Technologies, Uzbekistan (e-mail: murtazayeva1982@yandex.ru).

F. Zakirova is with Branch Center for Retraining and Advanced Training of Pedagogical Staff of the Higher Education at Tashkent University of Information Technologies, Uzbekistan (e-mail: f.zakirova@tuit.uz). enhancement of system of retraining and improving the qualifications of managerial and pedagogical personnel of higher educational institutions", advanced training of pedagogical staff of higher educational institutions (hereinafter referred to as academic staff) in different directions are carried out by the Basic Higher Educational Institutions in directions of advanced training to the 20 Centers of the country. As the Center for the organization of retraining and advanced training of academic staff in the direction of computer science and information technology; mathematical and software information systems; telecommunication technologies; hardware engineering and software engineering; radio electronic devices and systems; television technology; postal technology; library science; economics and management in the field of information and communication technologies (hereinafter referred to as ICT) is defined by the Branch Center for Retraining and Advanced Training of Pedagogical Staff of the Higher Education at Tashkent University of Information Technologies named after Muhammad al-Khwarizmi (hereinafter referred to as Branch Center of TUIT).

Research in the field of space radio-electronic communication systems is currently being updated. Space research is not only a new stage in the development of space science, it is a new stage in the development of a digital society. In order to develop domestic space science and make wide use of its achievements in the innovative development of the country, expand international cooperation in the field of space research and train qualified personnel, the Decree of the President of the Republic of Uzbekistan No. 5209 "On measures to develop space science in the Republic of Uzbekistan" was adopted in 2018. However, the use and further development of space systems and technologies without the training of competent specialists will not be effective. Therefore, the education system, in particular, the system of advanced training, must respond to these changes in a timely manner in designing a curriculum.

This article is devoted to the problem of curriculum design for advanced training courses for academic staff of the direction "Radio Electronic Devices and Systems" (hereinafter referred to as RED\&S) in the Republic of Uzbekistan. This raises the following range of issues:

- What is the target audience for advanced training courses and its needs?

- What are the goals and objectives of this course?

- What are the training modules and their content?

- How effective is the curriculum? 


\section{LITERATURE REVIEW}

\section{A. Approaches to Curriculum Development}

Analysis of the scientific literature on the issue of curriculum development over the past few years has shown that despite the important role of the curriculum in the educational theory and practice, there is no generally accepted approach to their designing. The article [1] draws attention to the complexity of issues related to curriculum design and emphasizes the need to improve curriculum development methods. Currently, academic educators use competently-oriented, problem-oriented, and integrated approaches to develop the curriculum.

The competency-based approach traces its roots back to pedagogical education in the 1960s, which involves the transition from traditional educational models to a competency-based model. Over the past few years, this approach has been actively used in the medical education system. For example, S. Kanofsky [2] developed Medical Education Basis based on the definition of a competency framework, H. Zhang, S. J. Jin, and S. Z. Du [3] develop a curriculum model for ESP of Master's level nursing education in a Chinese medicine university; $\mathrm{M}$. Neville-Norton and S. Cantwell [4] improved nursing program based on a competency-based approach. The competency-based approach has also been used in designing English curricula for economists [5] and mathematics to develop creativity [6].

The problem-oriented approach involves the use of analysis of existing problems in the development of the curriculum. For example, A. J. Edson, E. Phillips, Y. Slanger-Grant, and J. Stewart [7] proposed an ergonomic resource for design and implementation of problem-based curriculum. H. Y. Yilmaz and D. G. Esen [8] reviewed professional development programs based on on-the-job training for the development of school principals, deputy principals, and teachers.

Some authors propose using a comprehensive approach that is based on the use of a set of different approaches necessary for the effective implementation of a certain professional activity. M. Özerbaş [9] determines the levels of implementation of the common basic skills in the new curriculum based on constructivist learning approach specified by Ministry of Education from the viewpoints of teachers. G. T. S. Benavent and Sánchez-Reyes [10] identified Target situations which became centre stage in syllabus and materials design. K. P. Uchiyama and J. L. Radin [11] proposed the curriculum development process based on a visual representation of the curriculum in Higher Education. A. Mawdsley and S. Willis [12] showed that the result of implementing a curriculum designed so that all disciplines are horizontally integrated with each other. J. Choppin, Roth McDuffie, A. Drake C. and J. Davis [13] conceptualize curriculum ergonomics as a field that studies the interactions between users and curriculum materials. P. Kumari, R. Nayan, S. P. Aggarwal, and G. Baswani [14] identifies key concepts associated with inclusive education and discusses them in relation to issues and challenges in the reform of teacher education. Z. Zhang, Z. M. Lu, L. Ma, and $\mathrm{C}$. $\mathrm{Hu}$ [15] focused on the core concept of the design of the curriculum and the relationship between teaching content and learning resources, in particular, MOOC.

In the system of advanced training, T. Güneş, E. S. Demir, M. Hoplan, M. Çelikoğlu, and O. Güneş [16], E. Bozkurt, N. Kavak, H. Yamak, S. C. Bilici, O. Darici, and Y. Ozkaya [17] suggest using needs analysis when designing curricula.

Due to the rapid development of web 2.0 technologies by Y. Zhong, H. Tan, and Y. Peng [18], it is proposed to use Curriculum 2.0; P. Zimbrean [19] reveals the features of Online Curriculum.

\section{B. A Comprehensive Approach to Curriculum Design for Advanced Training Courses of Academic Staff}

Training in advanced training courses is carried out on the basis of the principles specified in the Resolution of the Cabinet of Ministers of the Republic of Uzbekistan No. 797 "On additional measures to further improve the system of advanced training for managers and teachers in higher educational institutions". This Resolution defines:

- Professional development of academic staff takes place at least once every 3 years;

- Training is carried out according to special programs in the amount of 288 hours, developed on the basis of a standard curriculum structure, 144 hours of which are carried out in the form of self-qualification on the job and 144 hours in the form of direct training in advanced training courses, of which 132 hours are allotted to classroom work, 12 hours for certification, which takes place in the form of tests and protection of qualifying project.

In the Republic of Uzbekistan, there is a tendency to standardize advanced training through the approval of standard curricula, on the basis of which certification of academic staff is carried out. The curricula of advanced training courses has been designed on the basis of Standard and approved by the Ministry of Higher and Secondary Specialized Education of the Republic of Uzbekistan for a period of no more than 3 years. In the Standard, the indicators of the distribution of the academic load across six modules are established, which correspond to the complex of knowledge, skills and competencies necessary for organizing scientific and pedagogical activities in Higher Education, namely, knowledge, skills and competencies:

1) Design of methodological documentation on the basis of current regulatory documentation;

2) Organization of the educational process based on innovative educational technologies;

3) Use of ICT in teaching and organizing independent work of students;

4) Practical use of foreign languages;

5) Use of methods of system analysis and decision-making in their scientific and pedagogical activities;

6) Teaching students of a specialty disciplines.

Curricula of specific areas are designed taking into account industry specifics in coordination with the Ministry of Higher and Secondary Specialized Education of the Republic of Uzbekistan.

The specifics of advanced training in the direction of RED\&S is determined by the fact that in the center of pedagogical impact was: 
1) An adult living in a digital world;

2) The qualified specialist with a master's degree in "5A350901-Mobile Communication Systems", "5A350801- Devices and Systems for Television, Radio Communication and Broadcasting";

3) The academic staff with specific experience in teaching disciplines such as "Satellite Communications and Applications", "Radio Relay and Satellite Communications";

4) The professor in the specialty "05.04.02-Systems and Devices of Radio Engineering, Radio Navigation, Radar and Television. Mobile, fiber-optic Communication Systems" with the scientific title of $\mathrm{PhD}$ (DSc).

Therefore, in designing a curriculum for advanced training in the field of RED\&S, we propose using a comprehensive approach that includes not only an analysis of the needs of academic staff, but also the knowledge and competencies necessary for organizing scientific and pedagogical activities in the conditions of digitalization of Higher Education.

\section{Methodology}

\section{A. Methods}

In the process of curriculum design for advanced training of academic staff, such methods as study, analysis, synthesis, generalization, conversation, observation, questionnaire, survey, and testing were used.

\section{B. Target Audience}

Academic staff teaching disciplines related to the aerospace industry was identified as the target group. The analysis of higher educational institutions of the Republic of Uzbekistan revealed that disciplines related to the aerospace industry are taught at the Tashkent University of Information Technologies and its five regional branches, at the Tashkent State Technical University and at the National University of Uzbekistan. For example, the Tashkent University of Information Technologies curriculum includes the discipline "Satellite Communications and Applications", which is taught for the bachelor's degree "5350100-Telecommunications Technologies", as well as the discipline "Radio Relay and Satellite Communications", which is taught for the master's degree "5A350901-Mobile Applications". These disciplines are conducted by academic staff of the Department of "Technologies of Mobile Communication" of the faculty of "Radio and Mobile Communication", who improve their professional competence in advanced training course in the direction of RED\&S.

\section{RESULTS}

\section{A. The Needs of Academic Staff}

Analysis of the needs of the selected target audience plays an important role in curriculum design. The results of the needs analysis largely determine the purpose and content of advanced training course. At the beginning of 2019, among academic staff of the Department of "Technologies of Mobile
Communication" of the faculty of "Radio and Mobile Communication", a questionnaire was conducted and conversation was held to determine the need for advanced training with a special emphasis on advanced training in the field of developing technologies and space communications. In total, 21 academic staff (AS) members and 9 masters (M) participated in the survey. The results of the questionnaire and interview are shown in Table I.

\begin{tabular}{|c|l|c|c|}
\hline \multicolumn{3}{|c}{ TABLE I: SURVEY RESULT } \\
\hline \multirow{2}{*}{ № } & \multicolumn{1}{|c|}{$\begin{array}{c}\text { Question: } \\
\text { Would you like to improve your } \\
\text { qualifications in the field of: }\end{array}$} & \multicolumn{2}{c|}{$\begin{array}{c}\text { Answer } \\
\text { "YES" in } \\
\text { the } \%\end{array}$} \\
\cline { 3 - 4 } & \multicolumn{1}{|c|}{$\begin{array}{c}\text { AS } \\
\text { Regulatory and educational } \\
\text { documentation }\end{array}$} & 15.7 & 3.9 \\
\hline 2 & Innovative educational technology & 67.5 & 21.6 \\
\hline 3 & ICT in education & 68.9 & 23.9 \\
\hline 4 & Practical foreign language & 61.3 & 68.8 \\
\hline 5 & System analysis and decision making & 31.8 & 33.7 \\
\hline 6 & In your specialty & 82.3 & 71.4 \\
\hline 7 & $\begin{array}{l}\text { On developing technologies and space } \\
\text { communications }\end{array}$ & 82.8 & 79.9 \\
\hline
\end{tabular}

Academic staff and masters note the desire to improve their knowledge primarily in their specialty, currently developing technologies and space communications; further on innovative educational technology and ICT, practical foreign language. Also, to identify the initial level of knowledge and competencies, a survey of academic staff was conducted to identify the level of self-esteem and testing to determine the actual knowledge. The results of self-analysis and testing are shown in Fig. 1.

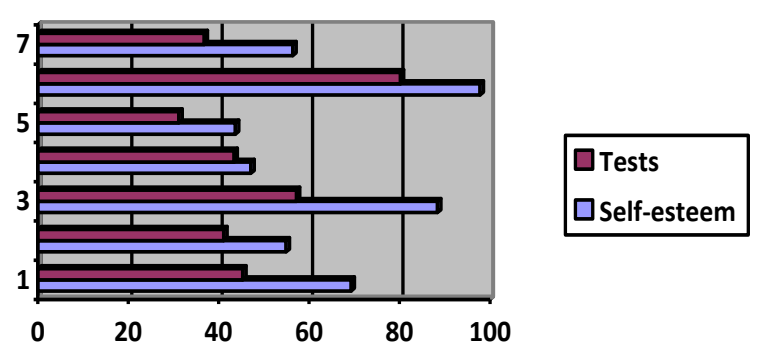

Fig. 1. The results of self-analysis and testing.

Thus, it was revealed that the self-esteem of academic staff is higher than the actual state by an average of $17.5 \%$. Wherein the average level of actual knowledge in all components (except for their specialty) is $47.9 \%$, which indicates the need for advanced training.

\section{B. Aim and Objectives of Advanced Training Course}

The aim of the advanced training course for academic staff in the field of RED\&S is to improve professional knowledge and competencies necessary for the design and implementation of the pedagogical process at a high scientific and methodological level based on innovative approaches and the development of creative activity of academic staff.

The objectives of the course are primarily determined by the development of professional knowledge and competencies of academic staff in the field of RED\&S on the basis of world practices in the field of special disciplines; 
secondly, improving their scientific and pedagogical knowledge and competencies in the field of systemic use of ICT, innovative educational technologies and practical foreign language.

\section{Structure of the Curriculum}

The General structure of the curriculum was developed on the basis of the standard structure and is presented in Table II.

\begin{tabular}{|c|l|c|}
\hline \multicolumn{3}{|c}{ TABLE II: CURRICULUM Structure } \\
\hline \multicolumn{1}{|c|}{ Training module } & Hours \\
\hline & & \\
\hline 1. & Regulatory and educational documentation & $\mathbf{1 0}$ \\
\hline 2. & Innovative educational technologies & $\mathbf{2 4}$ \\
\hline 3. & ICT in education & $\mathbf{1 6}$ \\
\hline 4. & Practical foreign language & $\mathbf{2 2}$ \\
\hline 5. & System analysis and decision making & $\mathbf{1 4}$ \\
\hline 6. & Specialty for the direction of RED\&S & $\mathbf{4 6}$ \\
\hline 6.1 & ICT Development Prospects & 10 \\
\hline 6.2 & Mobile Communication Systems & 14 \\
\hline 6.3 & Antennas in Radio Electronic Systems & 22 \\
\hline & TOTAL & $\mathbf{1 3 2}$ \\
\hline
\end{tabular}

It should be noted that the contents of the first five modules are common to all fields of advanced training. They differ in their practical application in each field of advanced training.

\section{Content of the Curriculum}

The aim of the first module is to familiarize academic staff with the basic regulatory framework and new concepts for the development of Higher Education in a digital society.

The main goal of the second module is to develop innovative culture and creativity of academic staff. In the content of this module, we included such relevant topics as: innovative pedagogy, interactive methods (Four Corners; Read, Think, Therefore; Placemat; Debate; What if?) and creative teaching methods (Scamper, Design of Thinking).

The third module introduces the didactic possibilities of ICT and allows to increase the knowledge and competence of academic staff in the use of e-learning and blended learning technologies (MOOC, LMS, MOODLE), as well as the practical use of global educational resources (ProQuest. Springer, Elsevier, Oxford University Press, Emerald, IVIS).

The fourth module is aimed at increasing the level of practical knowledge of a foreign language by academic staff and its wide use for the steady growth of their professional skills in pedagogical and scientific activities.

The purpose of the fifth module is to develop professional and managerial competencies of academic staff based on a systematic approach.

The sixth module is aimed at improving subject knowledge and competencies based on the latest achievements in the field of theory, scientific and applied research, technological progress and innovation in the direction of RED\&S. Based on the developing technologies of the digital society, the content of the first discipline (6.1. ICT Development Prospects) includes such topics as: Industry-4.0, ERP systems, IoT, Cloud technologies, Big Data, VR/AR. The content of the second discipline (6.2. Mobile Communication Systems) consists of such topics as broadband access networks, 4G technologies and standards, additional services in mobile communication systems, effective use of frequencies and elimination of interference in radio access networks, principles of design and optimization of the radio access network, comparison of physical and logical channels in different mobile systems. While further improving the content of this discipline, it was decided to add topics related to satellite systems, namely, communication systems using terrestrial satellites, communication principles and satellite orbits of the Earth, classification of satellite communication systems, the types of orbits used, satellite communication services, multi-station access systems in satellite communication systems. The content of the third discipline (6.3. Antennas in Radio Electronic Systems) includes topics such as the classification of antennas, their parameters and characteristics, and the capabilities of the MMANA-GAL program. Further improvement of the content of this discipline will include such topics as airborne and ground devices in communication systems, Inmarsat and Eutelracs satellites, VSAT satellite networks, Iridium satellite communication system, Global star satellite communication system, and geostationary satellite communication systems.

\section{DISCUSSION}

Evaluation is part of the curriculum design process and helps to achieve the goals set for the course, as well as measure results and provide reliable information on how successfully the curriculum was designed.

As an assessment of the five modules of our curriculum design, the results of a survey of academic staff of advanced training courses for 2019 at the Branch Center of TUIT were taken. In 2019, advanced training courses for the direction RED\&S were not planned. Therefore, only five modules from the new curriculum were evaluated. From November 2019 to January 2020, 91 academic staff members (including 15 assistants, 32 senior professors, 44 candidates and doctors of science) studied at the advanced training courses.

Entrance and exit testing contained questions on the five training modules of curriculum. The results of the entrance and exit testing were taken, and then the mean and standard deviation were calculated. The results of the entrance and exit testing are shown in Table III.

TABLE III: STATISTICAL DATA ENTRANCE AND EXIT TESTING

\begin{tabular}{|l|c|c|c|}
\hline Criteria & Average value & T-value & $\begin{array}{c}\text { Standard } \\
\text { deviation }\end{array}$ \\
\hline Entrance testing & 46.42 & \multirow{2}{*}{20.1} & $\begin{array}{c}1.97 \\
\text { Exit testing }\end{array}$ \\
\hline
\end{tabular}

Table III shows that the average value of the entrance testing was higher than the average value of the exit testing. the results of Student's t-test showed that there was a difference between the two testing $(t=20.1, p<0.05)$.

The participants noted that: a) received modern and original information about innovative teaching tools and about today's emerging digital society technologies; b) it was interesting to learn about the use of methods of system analysis and decision-making in practical scientific and pedagogical activities; c) in general, the course was difficult, but meaningful and effective.

\section{CONCLUSION}

The article reveals the stages of design and content of a 
comprehensive curriculum for advanced training of academic staff in the field of RED\&S, taking into account the analysis of needs, knowledge and competencies necessary for the organization of scientific and pedagogical activities in Higher Education. The first stage of the evaluation of the curriculum by participants revealed a positive attitude to the introduced changes in the five General Modules of the new curriculum for advanced training and gave fruitful results. Further studies will fully evaluate the entire curriculum, including the sixth module. We believe that this work has paved another step in the development of the theory and practice of adult education on the example of advanced training system of academic staff, filling in the missing link in the theory and methodology of lifelong education.

\section{CONFLICT OF INTEREST}

The authors declare no conflict of interest.

\section{AUTHOR CONTRIBUTIONS}

F. Zakirova created the topic of the article, organized the structure and finalized its; Sh. Pozilova organized review literature; G. Otamurodov designed the standart structure and content of the General Modules; U. Murtazayeva analyzed the data; Kh. Madaminov designed the content of special disciplines and assisted in the distribution of the questionnaire; all authors approved the final version.

\section{ACKNOWLEDGMENT}

This work is supported by the Head Scientific and Methodological Centre on Organising Retraining and Professional Development Courses for HEIs Managers and Pedagogical Staff under the Ministry of Higher and Secondary Specialized Education of the Republic of Uzbekistan and is carried out within the Erasmus+ project SPACECOM.

\section{REFERENCES}

[1] J. Sumsion and J. Goodfellow, "Identifying generic skills through curriculum mapping: A critical evaluation," High. Educ. Res. Dev., vol. 23, no. 3, pp. 329-346, 2004

[2] S. Kanofsky, "Competency-based medical education for physician assistants: The development of competency-based medical education and competency frameworks in the United States and Canada," Physician Assist. Clin., vol. 5, no. 1, pp. 91-107, 2020.

[3] H. Zhang, S. J. Jin, and S. Z. Du, "Developing a curriculum model of English teaching for master's degree nursing education in a Chinese medicine university," Int. J. Nurs. Sci., no. xxxx, pp. 1-6, 2020, doi: 10.1016/j.ijnss.2019.12.001.

[4] M. Neville-Norton and S. Cantwell, "Curriculum mapping in nursing education: A case study for collaborative curriculum design and program quality assurance," Teach. Learn. Nurs., vol. 14, no. 2, pp. 88-93, Apr. 2019, doi: 10.1016/j.teln.2018.12.001.

[5] L. R. Ismagilova and O. V. Polyakova, "The problem of the syllabus design within the competence approach based on the course 'English for master degree students in economics (advanced level)," Procedia Soc. Behav. Sci., vol. 152, pp. 1095-1100, 2014, doi: 10.1016/j.sbspro.2014.09.281.

[6] L. L. Hadar and M. Tirosh, "Creative thinking in mathematics curriculum: An analytic framework," Think. Ski. Creat., vol. 33, no. September 2018, p. 100585, 2019, doi: 10.1016/j.tsc.2019.100585.

[7] A. J. Edson, E. Phillips, Y. Slanger-Grant, and J. Stewart, "The arc of learning framework: An ergonomic resource for design and enactment of problem-based curriculum," Int. J. Educ. Res., vol. 93, pp. 118-135, Jan. 2019, doi: 10.1016/J.IJER.2018.09.020.
[8] H. Y. Yilmaz and D. G. Esen, "An investigation on in-service trainings of the ministry of national education (MONE)," Procedia - Soc. Behav. Sci., vol. 186, pp. 79-86, 2015, doi: 10.1016/j.sbspro.2015.04.019.

[9] M. A. Özerbaş, "Evaluation of new primary education curriculum based on constructivist learning approach through the viewpoints of teachers," Procedia - Soc. Behav. Sci., vol. 174, pp. 2292-2300, 2015, doi: $10.1016 /$ j.sbspro.2015.01.890.

[10] G. T. Benavent and S. Sánchez-Reyes, "Target situation as a key element for esp (law enforcement) syllabus design," Procedia - Soc. Behav. Sci., vol. 173, pp. 143-148, 2015, doi 10.1016/j.sbspro.2015.02.044.

[11] K. P. Uchiyama and J. L. Radin, "Curriculum mapping in higher education: A vehicle for collaboration," Innov. High. Educ., vol. 33, no. 4, pp. 271-280, Jan. 2009, doi: 10.1007/s10755-008-9078-8.

[12] A. Mawdsley and S. Willis, "Exploring an integrated curriculum in pharmacy: Students' perspectives on the experienced curriculum and pedagogies supporting integrative learning," Curr. Pharm. Teach. Learn., vol. 11, no. 5, pp. 450-460, May 2019, doi: 10.1016/j.cptl.2019.02.006.

[13] J. Choppin, A. R. McDuffie, C. Drake, and J. Davis, "Curriculum ergonomics: Conceptualizing the interactions between curriculum design and use," Int. J. Educ. Res., vol. 92, pp. 75-85, Jan. 2018, doi 10.1016/j.ijer.2018.09.015

[14] P. Kumari, R. Nayan, S. P. Aggarwal, and G. Baswani, "Rethinking teacher education programmes for inclusive classrooms: Issues and challenges in India," Int. J. Inf. Educ. Technol., vol. 9, no. 2, pp. 143-148, 2019, doi: 10.18178/ijiet.2019.9.2.1189.

[15] Z. Zhang, Z. M. Lu, L. Ma, and C. Hu, "A construction method of MOOC courses in colleges and universities," Int. J. Inf. Educ. Technol., vol. 9, no. 10, pp. 735-740, 2019, doi: 10.18178/ijiet.2019.9.10.1295.

[16] T. Güneș, E. S. Demir, M. Hoplan, M. Çelikoğlu, and O. Güneș, "The perceptions and needs of science and primary school teachers about in-service training," Procedia - Soc. Behav. Sci., vol. 15, pp. 1102-1109, 2011, doi: 10.1016/j.sbspro.2011.03.246.

[17] E. Bozkurt, N. Kavak, H. Yamak, S. C. Bilici, O. Darici, and Y. Ozkaya, "Secondary school teachers' opinions about in-service teacher training: A focus group interview study*," Procedia - Soc. Behav. Sci., vol. 46, no. 2010, pp. 3502-3506, 2012, doi: 10.1016/j.sbspro.2012.06.093.

[18] Y. Zhong, H. Tan, and Y. Peng, "Curriculum 2.0 and student content-based language pedagogy," System, vol. 84, pp. 76-86, 2019, doi: 10.1016/j.system.2019.06.001.

[19] P. Zimbrean, "Online curriculum in transplant psychiatry," Psychosomatics, pp. 1-7, 2019, doi: 10.1016/j.psym.2019.12.006.

Copyright $\odot 2021$ by the authors. This is an open access article distributed under the Creative Commons Attribution License which permits unrestricted use, distribution, and reproduction in any medium, provided the original work is properly cited ( $\underline{\text { C BY } 4.0)}$.

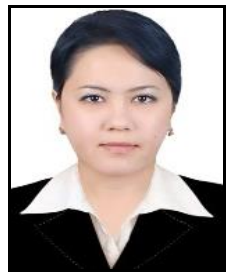

Shanoza Pozilova is a lecturer at the Department of Information educational technologies, Tashkent University of Information Technologies, Uzbekistan. She is a PhD in pedagogical science, the author of more than 20 articles and 2 textbooks. Her research interests include the problems of using ICT in the vocational education, creativity in education, design thinking, curriculum and instruction design and teaching for creativity.

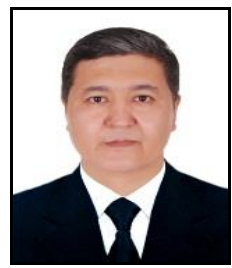

Khaydar Madaminov is a lecturer at the Department of Technology Mobile Communications, Tashkent University of Information Technologies, Uzbekistan The research experience as follows: Global satellite communication system. He is an author of about 10 articles. The focus of his publications is on communication systems, experimental research of weakening of mobile signals of the field in the premises of buildings in his papers and project reports.

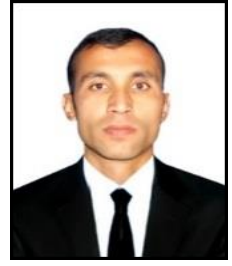

Golibjon Otamurodov works at the Head Scientific and Methodological Center under the Ministry of Higher and Secondary Specialized Education, Uzbekistan. $\mathrm{He}$ is a $\mathrm{PhD}$ in pedagogical science, the author of more than 15 articles and 2 patents. The focus of his publications is on information and methodological system for the development of managerial competence of heads of Higher Education in his papers, project reports, and patents. 


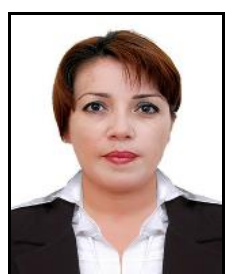

Umida Murtazaeva is a lecturer at the Department of Computer System, Samarkand branch of the Tashkent University of Information Technologies, Samarkand, Uzbekistan. Her research interests include the problems of using ICT in higher education. She creates innovation ideas in teaching for students in higher education to develop imaginative thinking and inspire students' learning motivation to put original ideas into students' projects

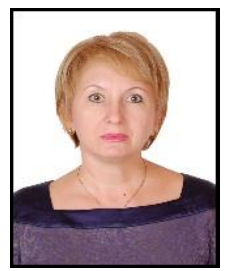

Feruza Zakirova is a director of the Branch Center for Retraining and Advanced Training of Pedagogical Staff of the Higher Education at Tashkent University of Information Technologies, Uzbekistan Also she is professor at the Head Scientific and Methodological Center under the Ministry of Higher and Secondary Specialized Education. The author of more than 150 articles and 6 textbooks. Her research interests include the problems of using ICT and innovative technologies in education. 